\title{
Foliar Urea Applications Increase Yeast Assimilable Nitrogen Concentration and Alcoholic Fermentation Rate in 'Red Spy' Apples Used for Cider Production
}

\author{
Adam D. Karl and Michael G. Brown \\ School of Integrative Plant Science, Horticulture Section, Cornell University, \\ 121 Plant Science Building, Ithaca, NY 14853
}

Sihui Ma, Ann Sandbrook, and Amanda C. Stewart

Department of Food Science and Technology, Virginia Polytechnic Institute and State University, HABB1 Room 401F, 1230 SW Washington Street, Blacksburg, VA 24060

\section{Lailiang Cheng}

School of Integrative Plant Science, Horticulture Section, Cornell University, 120 Plant Science Building, Ithaca, NY 14853

Anna Katharine Mansfield

Department of Food Science, Cornell AgriTech, 107 Food Research Lab, Geneva, NY 14456

Gregory M. Peck

School of Integrative Plant Science, Horticulture Section, Cornell University, 121 Plant Science Building, Ithaca, NY 14853

Additional index words. amino acid, foliar fertilization, hard cider, hydrogen sulfide, Malus $\times$ domestica Borkh., primary amino nitrogen, yeast assimilable nitrogen

Abstract. Yeast assimilable nitrogen (YAN) can be a limiting nutritional factor for Saccharomyces cerevisiae yeast when fermenting apple (Malus $\times$ domestica Borkh.) juice into hard cider. Endogenous YAN concentrations in apples are often below the recommended thresholds to completely use all of the fermentable sugar and minimize the production of off-flavors, such as hydrogen sulfide. Cider producers supplement apple juice with exogenous nitrogen to increase YAN. Urea, commonly applied to apple orchards to increase fruit size and yields, was tested for its ability to increase endogenous apple juice YAN. Starting 6 weeks before harvest in 2017 and 2018, a 1\% urea solution was applied to 'Red Spy' apple trees one, three, or five times to create low-, medium-, and high-rate treatments, respectively. Relative to the control, the high treatment increased YAN by $229 \%$ in 2017 and by $408 \%$ in 2018 . More than $90 \%$ of the YAN in all juice samples was composed of primary amino nitrogen (PAN). Among all treatments, PAN mostly comprised asparagine, and as urea applications increased, the relative concentration of asparagine also increased. Aspartic acid and then glutamic acid were the second and third most abundant amino acids in all treatments, respectively, but comprised less of the total PAN as the number of urea applications increased. Soluble solid concentration, pH, titratable acidity, and total polyphenol concentration were not different among treatments. There was a positive correlation between increased urea application rate and the maximum fermentation rate, which resulted in a shorter fermentation duration. Increasing the number of urea applications was also correlated with greater hydrogen sulfide $\left(\mathrm{H}_{2} \mathrm{~S}\right)$ production in juice fermented from fruit harvested in 2017 but not for fruit harvested in 2018 . No residual $\mathrm{H}_{2} \mathrm{~S}$ was found in the finished cider from any treatment. Increasing the number of urea applications was estimated to be less expensive than supplementing the juice with Fermaid $O^{\mathrm{TM}}$. There would have been no cost savings if Fermaid $K^{\mathrm{TM}}$ was used as an exogenous nitrogen source. Foliar urea applications were estimated to be more expensive than supplementing juice with diammonium phosphate. This study demonstrated that foliar urea applications can effectively increase YAN concentration in cider apples while not negatively affecting other juice quality attributes.

Production of hard cider (fermented apple juice) in the United States has grown from 23.1 million liters in 2007 to 173.4 million liters in 2017 , making cider the fastest grow- ing beverage sector in the country during this period (Alcohol and Tobacco Tax and Trade Bureau, 2008, 2018). The growth of the cider industry offers apple (Malus $\times$ domestica
Borkh.) producers an opportunity to expand and diversify into a niche commodity with a high price premium (Peck and Knickerbocker, 2018). To ensure the success of these new enterprises, additional research is needed to determine how orchard management affects cider quality. In particular, there has been minimal research on how preharvest nitrogen fertilizer management in apple orchards might affect economic returns, fruit quality, fermentation dynamics, and the sensory attributes of the finished product.

Nitrogen is a macronutrient that is essential for plant metabolism, and its role in freshmarket apple production is well studied (Cheng and Fuchigami, 2002; Lea and Beech, 1978; Merwin and Stiles, 1994; Santos et al., 2016; Wargo et al., 2003). From budbreak to just after bloom, apple trees use stored nitrogen reserves to support vegetative growth, flowering, and fruit set (Cheng and Raba, 2009). For the remainder of the growing season, apple trees acquire nitrogen from the soil or from nitrogen applied to the leaf surface (referred to as foliar applications). Nitrogen-deficient orchards are found in many regions of the world, and it is a common practice to apply nitrogen fertilizers through both ground and foliar means (Merwin and Stiles, 1994). Foliar nitrogen applications in the late summer and fall ensure sufficient reserves for the following spring. During the fall, Dong et al. (2005) found that leaf nitrogen uptake is more efficient than root uptake.

When nitrogen is limited in apple trees, there is often a decrease in fruit size, yield, and soluble solid concentrations (Xia et al., 2009). Conversely, excessive nitrogen fertilization in mature orchards can lead to decreased fruit quality by reducing flesh firmness and red peel color (Fallahi et al., 1997; Wang and Cheng, 2011). As a diagnostic tool, total nitrogen concentration is measured from mature apple leaves once terminal shoot growth has subsided. A target leaf nitrogen content between $2.2 \%$ and $2.4 \%$ is recommended for mature hard-fleshed and processing cultivars (Stiles and Reid, 1991). Currently, there are no standard nitrogen fertilization guidelines for cider apple production in the United States.

Increasing fruit nitrogen concentration may be beneficial for cider fermentation. Specifically, YAN comprises the nitrogen compounds that are metabolized by Saccharomyces cerevisiae yeast for cell division and growth during alcoholic fermentation of fruit juice (Bell and Henschke, 2005). Yeast assimilable nitrogen is composed of free amino nitrogen (FAN), ammonia ions, and some short oligopeptides (Bell and Henschke, 2005). Unlike wine grapes (Vitis vinifera L.) that contain a variable, but large, proportion of YAN as ammonia, FAN comprises the vast majority of YAN in apples (Bell and Henschke, 2005; Ma et al., 2018). Furthermore, although composition of amino acids vary by apple cultivar, asparagine is typically the most abundant amino acid in the fruit (Ma et al., 2018). However, ammonia is 
preferentially used and more rapidly metabolized by $S$. cerevisiae than most organic nitrogen sources (Crépin et al., 2012). There are no studies that specify the target YAN concentration for the cider industry; however, recent studies have shown that apple juice is often deficient in YAN according to standards developed for the wine industry. Although, recommendations vary by region, cultivar, and wine style, $140 \mathrm{mg} \cdot \mathrm{L}^{-1}$ is often cited as the minimum YAN concentration for successful fermentations (Bell and Henschke, 2005; Ma et al., 2018; Peck et al., 2016; Tahim and Mansfield, 2019).

Yeast assimilable nitrogen deficiencies can result in slow or incomplete wine and cider fermentations (Bell and Henschke, 2005; Vilanova et al., 2007). The composition of YAN can impact chemical and sensory attributes of the finished product (Boudreau et al., 2017a; Herraiz and Ough, 1993). In particular, low YAN is known to increase the production of hydrogen sulfide $\left(\mathrm{H}_{2} \mathrm{~S}\right)$, a malodorous reduced sulfur compound. Additionally, although some volatile aromatics in cider are derived from compounds produced in the fruit, most are secondary metabolites produced by yeast during alcoholic fermentation (Xu et al., 2007). In particular, fusel alcohols and acetate esters can be formed from the byproducts of amino acid metabolism (Sumby et al., 2010). Sufficient YAN is also critical for catalyzing the metabolic pathways of fatty acids in yeast that produce ethyl esters as a byproduct (Saerens et al., 2010). Increasing YAN concentration in wine and cider fermentations has been found to increase both ethyl and acetate ester concentrations, which contribute a large proportion of the fruity aroma of the finished product (Garde-Cerdán and Ancín-Azpilicueta, 2008; Santos et al., 2016; Tahim and Mansfield, 2019).

Proprietary exogenous nitrogen supplements are commercially available and commonly added to fruit juice fermentations to address YAN deficiencies. Diammonium phosphate (DAP) is probably the most commonly used. However, many wine and cider

Received for publication 18 Mar. 2020. Accepted for publication 5 June 2020.

Published online 15 July 2020.

We thank David Zakalik, Lindsay Springer, Amy Moore, and the Cornell Orchards staff for their help and guidance during this project. Graduate assistantship funding for A. Karl was provided by Cornell University's College of Agriculture and Life Sciences and School of Integrative Plant Science-Horticulture Section. This material is based on work supported by the National Institute of Food and Agriculture, U.S. Department of Agriculture, Hatch, under accession 1014042, the American Cider Association, the Angry Orchard Cider Company, LLC, and the Arthur Boller Research Award.

G.M.P. is the corresponding author. E-mail: gmp32@cornell.edu.

This is an open access article distributed under the CC BY-NC-ND license (https://creativecommons.org/ licenses/by-nc-nd/4.0/). producers prefer adding yeast nutrient supplements with greater PAN than ammonia concentrations to limit initial alcoholic fermentation rates, temperature increases from increased metabolic rates that can stress yeast cells, and changes to sensory character imparted by high ammonia additions (Charoenchai et al., 1998; Tahim and Mansfield, 2019). These high PAN supplements are typically composed of inactivated dry yeast cells and contain minerals, sterols, and vitamins important for yeast metabolism (Ángeles PozoBayón et al., 2009).

Preharvest foliar nitrogen applications in vineyards have been found to be effective means of increasing grape YAN concentrations. For example, Moss (2016) found a cumulative application of $30 \mathrm{~kg} \cdot \mathrm{ha}^{-1}$ of nitrogen applied as urea to foliage was capable of more than doubling the YAN concentration in 'Sauvignon blanc' and 'Petit Manseng' grapes. These foliar applications were also more effective in increasing must YAN than a $60 \mathrm{~kg} \cdot \mathrm{ha}^{-1}$ ground application of nitrogen as calcium nitrate. Foliar urea applications may therefore also be an effective means of increasing apple fruit YAN for cider production. Additionally, if orchard nitrogen fertilization is capable of increasing apple YAN, it is more likely to be in PAN form than ammonia. When urea is added directly to juice, it can form ethyl carbamate (a carcinogen), and thus urea is forbidden as a juice or wine grape must nitrogen supplement (Butzke and Bisson, 1997; Witte, 2011). However, urea applied to the tree is metabolized to ammonia and carbon dioxide by urease enzymes and is a common and safe horticultural practice.

To investigate the feasibility of orchard foliar fertilization for increasing apple juice YAN, 'Red Spy' apple trees located in Lansing, NY, were provided with three rates of foliar urea applications during the 6 weeks before harvest. The experiment was repeated on different trees within the same orchard over 2 years. The goal of the study was to determine whether foliar nitrogen applications in apple orchards, which are commonly applied to apple orchards during the late summer and fall, can cost-effectively improve cider apple juice quality. We hypothesized that foliar urea applications would increase juice YAN and fermentation rates and decrease $\mathrm{H}_{2} \mathrm{~S}$ production during fermentation of the juice without altering other important fruit and juice attributes, such as total polyphenol, soluble solid, and titratable acid concentrations.

\section{Materials and Methods}

Orchard site. This study was conducted in 2017 and 2018 at a Cornell University Agricultural Experiment Station research orchard in Lansing, NY (lat. 42.573875, long. $-76.596111)$ on Ovid silt loam soils with a $0^{\circ}$ to $6^{\circ}$ slope (Soil Survey Staff, 2014). The trees, Malus $\times$ domestica Borkh cv. 'Red Spy' grafted onto 'Budagovsky 9' dwarfing rootstock were trained as a vertical axis. The
Table 1. Treatment timing of foliar urea applications on cv. 'Red Spy' apple trees grown in Lansing, NY.

\begin{tabular}{lccccc}
\hline & \multicolumn{5}{c}{ Weeks before harvest } \\
\cline { 2 - 6 } Treatment & 6 & 5 & 4 & 3 & 2 \\
\hline Control & & & & & \\
Low & & & $\times$ & & \\
Medium & & $\times$ & $\times$ & $\times$ & \\
High & $\times$ & $\times$ & $\times$ & $\times$ & $\times$ \\
\hline
\end{tabular}

orchard was planted in 2012 with $1.2 \mathrm{~m}$ between trees and $3.7 \mathrm{~m}$ between rows. Over the course of the experiment, the trees were uniformly managed using standard pest control and pruning practices for the region (Agnello et al., 2019).

Experimental design. Three foliar nitrogen treatments were applied starting 6 weeks before harvest in both years of the study. The study was a randomized complete block design, with six replications of single tree experimental units. Different trees within the orchard were used in each field season, and at a minimum, two buffer trees were located between treatment trees. Urea granular fertilizer dissolved in water at a concentration of $10 \mathrm{~g} \cdot \mathrm{L}^{-1}$ was applied to treatment trees using a Solo 451 backpack mist blower (Newport News, VA) at an equivalent rate of $935 \mathrm{~L}$ water $/$ ha for a $4.3 \mathrm{~kg} \mathrm{~N} / \mathrm{ha}$ application rate. The number of urea applications established low (1 application), medium (3 applications), high (5 applications), and control (0 applications) treatments as per the schedule listed in Table 1. The 2017 foliar applications were made on 24 Aug., 31 Aug., 7 Sept., 14 Sept., and 21 Sept.; the 2018 applications were made on 23 Aug., 30 Aug., 6 Sept., 13 Sept., and 20 Sept.

Harvest and fruit measurements. Harvest occurred on 5 Oct. 2017 and 5 Oct. 2018. All fruit from each sample tree was harvested and weighed. Ten-fruit subsamples were measured for mass, percent peel blush, starch pattern index (SPI), flesh firmness, and chlorophyll a content. Peel blush was visually approximated as the area of the fruit peel with red coloration. Starch pattern index was rated on a 1 - to 8 -point scale, with $1=0 \%$ starch degradation and $8=100 \%$ starch degradation (Blanpied and Silsby, 1992). The SPI was also used to determine harvest date, with a target value of 6 . Flesh firmness was measured on both the sun and the shade exposed side of each fruit along the equator after removing the peel with a penetrometer (GS Fruit Texture Analyzer; Güss, Strand, South Africa) fitted with an 11.1-mm tip. Chlorophyll a content was measured on a 0 - to 3-point index with a Turoni 53500 DA meter (Forli, Italy) on the sun and the shade side of each apple along the equator. Ten exposed, nondamaged leaves from shoot midsections were taken from both sides of each tree between 1 and $2 \mathrm{~m}$ in height the day before harvest (in both 2017 and 2018) and submitted to the Cornell Nutrient Analysis Laboratory for combustion analysis of total nitrogen as per standard protocols (VarioMax CNS; Elementar Analysensysteme $\mathrm{GmbH}$, Langenselbold, 
Germany). Trunk cross sectional area (TCSA) was calculated by measuring trunk circumference at $30 \mathrm{~cm}$ above the graft union and recorded each fall after the trees defoliated.

Milling, juicing, and fermentation. Ten fruit from each experimental unit were randomly selected and milled and pressed in a Norwalk 280 juicer (Bentonville, AR) to make a juice sample. After settling at $2{ }^{\circ} \mathrm{C}$ overnight, juice was racked off sediment and aliquoted into two 200-mL samples in 250-mL erlenmeyer flasks. Potassium metabisulfite solution $(100 \mu \mathrm{L}$ of a $17.5 \% \mathrm{w} / \mathrm{v}$ to yield $50 \mathrm{mg} \cdot \mathrm{L}^{-1}$ of free $\mathrm{SO}_{2}$ ) was added to each flask and stirred $24 \mathrm{~h}$ before yeast was inoculated.

To rehydrate yeast for inoculation, $5 \mathrm{~g}$ of S. cerevisiae UCD-522 yeast was rehydrated in $100 \mathrm{~mL} 40{ }^{\circ} \mathrm{C}$ water for $20 \mathrm{~min}$ and then $100 \mathrm{~mL}$ of a juice sample added over $5 \mathrm{~min}$. Two milliliters of rehydrated yeast solution was then added to each fermentation flask. Each flask was fitted with a Kitigawa 120SB $\mathrm{H}_{2} \mathrm{~S}$ detector tube (Pompton Lakes, NJ) that was inserted into a single-hole stopper. The detector tubes contain lead acetate, which reacts with $\mathrm{H}_{2} \mathrm{~S}$ to form gray-colored lead sulfide. This method, originally reported by Ugliano and Henschke (2010), has been used to monitor $\mathrm{H}_{2} \mathrm{~S}$ during cider fermentations by Boudreau et al. (2017b). Color change in the $\mathrm{H}_{2} \mathrm{~S}$ detector tubes was recorded every $24 \mathrm{~h}$. Flasks were kept at $18{ }^{\circ} \mathrm{C}$ and weighed every $24 \mathrm{~h}$ to track fermentation rates by calculating the mass of sugar metabolized from mass loss

Table 2. Partial budget model variables and parameters used to compare foliar urea applications and exogenous nitrogen fermentation supplementation costs. Nitrogen supplement costs were obtained in Apr. 2019.

\begin{tabular}{|c|c|c|}
\hline Description & Cost & Source \\
\hline Foliar urea applications & $\$ 37.69 / \mathrm{ha}$ & Farris et al. (2013) \\
\hline Urea & $\$ 0.56 / \mathrm{kg}$ & Nutrien \\
\hline Fermaid $\mathrm{O}^{\mathrm{TM}}$ & $\$ 33.80 / \mathrm{kg}$ & Scott Laboratories \\
\hline Fermaid $\mathrm{K}^{\mathrm{TM}}$ & $\$ 15.70 / \mathrm{kg}$ & Scott Laboratories \\
\hline Diammonium phosphate & $\$ 2.60 / \mathrm{kg}$ & BSG Wine \\
\hline
\end{tabular}

of $\mathrm{CO}_{2}$. Maximum fermentation rate was determined by calculating the slope of the fermentation curve during the exponential phase of yeast growth. Flasks were stirred for $5 \mathrm{~min}$ at $120 \mathrm{rpm}$ on an orbital shaker twice a day to keep yeast in suspension. Once fermentation rate fell below $0.2 \mathrm{~g} \mathrm{CO}_{2} / \mathrm{d}$, fermentations were considered completed. Cider samples were then racked off the fine lees and stored at $-80^{\circ} \mathrm{C}$.

Juice chemistry. Soluble solid concentration, $\mathrm{pH}$, titratable acidity (TA), YAN (PAN and ammonium ion), and total polyphenol concentrations via the Folin Ciocalteu assay were measured in each juice sample. Soluble solid concentration was measured with an Atago PAL-1 digital refractometer (Tokyo, Japan) and reported as ${ }^{\circ}$ Brix. Juice $\mathrm{pH}$ and TA were measured with an automatic titrator (Unitrode $\mathrm{pH}$ meter, 778 sample processor, and 800 Dosino dosing device; Metrohm, Herisau, Switzerland). A 5-mL juice sample was titrated against a $0.1 \mathrm{M} \mathrm{NaOH}$ solution to an endpoint of $\mathrm{pH} 8.2$ and expressed in grams per liter of malic acid equivalents. Total polyphenols were measured with the Folin Ciocalteu assay in a 96-well microplate at $\lambda$ $765 \mathrm{~nm}$ (Singleton and Rossi, 1965). Folin

Table 3. Tree and fruit measurements of 'Red Spy' apple trees grown in Lansing, NY, that had 0 (control), 1 (low), 3 (medium), or 5 (high) foliar urea applications. Values are means $\pm \operatorname{SE}(\mathrm{n}=6$ per year).

\begin{tabular}{|c|c|c|c|c|c|c|c|c|c|}
\hline $\mathrm{Yr}$ & Treatment & Yield (kg/tree) & $\begin{array}{c}\text { Yield efficiency } \\
(\mathrm{kg} / \mathrm{TCSA})\end{array}$ & Mass (g) & Firmness $(\mathrm{N})$ & $\begin{array}{c}\text { Starch pattern } \\
\text { index }(1-8)\end{array}$ & Peel blush (\%) & $\begin{array}{c}\text { Chlorophyll a } \\
\text { index }\end{array}$ & $\begin{array}{c}\text { Leaf } \\
\text { nitrogen }(\%)\end{array}$ \\
\hline \multirow[t]{4}{*}{2017} & Control & $16.7 \pm 2.1$ & $1.2 \pm 0.2$ & $347.4 \pm 14.9$ & $62.8 \pm 1.8$ & $6.8 \pm 0.2$ & $84.0 \pm 1.3$ & $1.02 \pm 0.26$ & $2.2 \pm 0.1$ \\
\hline & Low & $15.1 \pm 1.2$ & $1.0 \pm 0.1$ & $367.2 \pm 18.1$ & $57.9 \pm 1.9$ & $6.9 \pm 0.2$ & $79.5 \pm 1.7$ & $1.08 \pm 0.09$ & $2.3 \pm 0.1$ \\
\hline & Medium & $18.5 \pm 1.3$ & $1.1 \pm 0.2$ & $368.0 \pm 15.7$ & $63.8 \pm 1.6$ & $6.5 \pm 0.2$ & $78.2 \pm 1.8$ & $1.22 \pm 0.06$ & $2.3 \pm 0.1$ \\
\hline & High & $18.1 \pm 2.7$ & $1.0 \pm 0.1$ & $357.4 \pm 12.1$ & $59.0 \pm 2.8$ & $6.9 \pm 0.3$ & $75.0 \pm 1.6$ & $1.13 \pm 0.09$ & $2.3 \pm 0.1$ \\
\hline \multirow[t]{4}{*}{2018} & Control & $20.7 \pm 1.3$ & $1.3 \pm 0.1$ & $223.0 \pm 19.3$ & $59.0 \pm 4.1$ & $6.0 \pm 0.2$ & $79.0 \pm 1.7$ & $1.16 \pm 0.05$ & $2.2 \pm 0.0$ \\
\hline & Low & $19.8 \pm 1.5$ & $1.3 \pm 0.1$ & $230.8 \pm 17.1$ & $58.3 \pm 1.4$ & $5.7 \pm 0.4$ & $81.0 \pm 1.6$ & $1.2 \pm 0.07$ & $2.2 \pm 0.0$ \\
\hline & Medium & $21.9 \pm 1.9$ & $1.3 \pm 0.1$ & $239.1 \pm 8.1$ & $59.7 \pm 5.9$ & $6.0 \pm 0.3$ & $74.0 \pm 2.0$ & $1.36 \pm 0.07$ & $2.3 \pm 0.1$ \\
\hline & High & $20.5 \pm 1.4$ & $1.3 \pm 0.1$ & $223.0 \pm 8.1$ & $60.8 \pm 9.6$ & $6.3 \pm 0.1$ & $72.0 \pm 2.0$ & $1.53 \pm 0.07$ & $2.4 \pm 0.0$ \\
\hline \multirow[t]{4}{*}{ Combined } & Control & $18.7 \pm 1.2$ & $1.3 \pm 0.1$ & $285.2 \pm 22.1$ & $60.9 \pm 1.8$ & $6.4 \pm 0.2$ & $81.5 \pm 1.3$ & $1.09 \pm 0.06$ & $2.2 \pm 0.0$ \\
\hline & Low & $17.5 \pm 1.2$ & $1.1 \pm 0.1$ & $299.0 \pm 22.1$ & $58.2 \pm 1.8$ & $6.3 \pm 0.2$ & $80.3 \pm 1.3$ & $1.14 \pm 0.06$ & $2.2 \pm 0.0$ \\
\hline & Medium & $20.2 \pm 1.2$ & $1.2 \pm 0.1$ & $303.5 \pm 21.2$ & $61.8 \pm 2.1$ & $6.3 \pm 0.2$ & $76.1 \pm 1.6$ & $1.29 \pm 0.05$ & $2.3 \pm 0.1$ \\
\hline & High & $19.3 \pm 0.9$ & $1.2 \pm 0.1$ & $290.2 \pm 21.4$ & $59.9 \pm 3.3$ & $6.6 \pm 0.2$ & $73.5 \pm 1.8$ & $1.33 \pm 0.08$ & $2.3 \pm 0.0$ \\
\hline \multirow[t]{3}{*}{$P$ value } & Treatment & 0.265 & 0.607 & 0.798 & 0.623 & 0.280 & 0.002 & $<0.001$ & 0.013 \\
\hline & Year & 0.010 & 0.011 & $<0.001$ & 0.370 & 0.003 & 0.099 & 0.038 & 0.058 \\
\hline & Treatment $\times$ year & 0.482 & 0.463 & 0.838 & 0.818 & 0.251 & 0.868 & 0.066 & 0.231 \\
\hline
\end{tabular}

TCSA $=$ trunk cross sectional area.

Table 4. Juice chemistry from 'Red Spy' apples from trees grown in Lansing, NY, that had 0 (control), 1 (low), 3 (medium), or 5 (high) foliar urea applications. Values are means \pm SE $(n=6$ per year).

\begin{tabular}{|c|c|c|c|c|c|c|c|c|}
\hline $\mathrm{Yr}$ & Treatment & $\begin{array}{l}\text { Soluble solid } \\
\text { concn ( }\left({ }^{\circ} \text { Brix }\right)\end{array}$ & $\mathrm{pH}$ & $\begin{array}{l}\text { Titratable acidity } \\
\text { (g malic acid/L) }\end{array}$ & $\begin{array}{l}\text { Total polyphenols } \\
\text { (g GAE/L) }\end{array}$ & $\begin{array}{l}\text { Yeast assimilable } \\
\text { nitrogen }\left(\mathrm{mg} \cdot \mathrm{L}^{-1}\right)\end{array}$ & $\begin{array}{c}\text { Primary amino } \\
\text { nitrogen }\left(\mathrm{mg} \cdot \mathrm{L}^{-1}\right)\end{array}$ & $\begin{array}{c}\text { Ammonia } \\
\left(\mathrm{mg} \cdot \mathrm{L}^{-1}\right)\end{array}$ \\
\hline \multirow[t]{4}{*}{2017} & Control & $14.1 \pm 0.4$ & $3.50 \pm 0.04$ & $6.8 \pm 0.3$ & $0.71 \pm 0.10$ & $30.7 \pm 3.3$ & $27.5 \pm 3.5$ & $1.9 \pm 1.3$ \\
\hline & Low & $13.9 \pm 0.4$ & $3.52 \pm 0.03$ & $6.3 \pm 0.2$ & $0.66 \pm 0.07$ & $37.5 \pm 2.8$ & $35.8 \pm 2.7$ & $1.7 \pm 0.2$ \\
\hline & Medium & $14.1 \pm 0.3$ & $3.49 \pm 0.02$ & $6.9 \pm 0.2$ & $0.84 \pm 0.01$ & $54.7 \pm 6.6$ & $52.5 \pm 6.5$ & $2.2 \pm 0.3$ \\
\hline & High & $4.6 \pm 0.4$ & $3.54 \pm 0.03$ & $7.0 \pm 0.3$ & $0.71 \pm 0.08$ & $101.0 \pm 10.5$ & $96.6 \pm 10.1$ & $4.4 \pm 0.7$ \\
\hline \multirow[t]{4}{*}{2018} & Control & $12.8 \pm 0.1$ & $3.41 \pm 0.02$ & $7.0 \pm 0.2$ & $0.52 \pm 0.02$ & $15.7 \pm 1.0$ & $13.8 \pm 1.1$ & $1.9 \pm 0.4$ \\
\hline & Low & $13.0 \pm 0.3$ & $3.42 \pm 0.02$ & $7.1 \pm 0.3$ & $0.62 \pm 0.04$ & $35.5 \pm 6.6$ & $33.3 \pm 6.5$ & $2.2 \pm 0.3$ \\
\hline & Medium & $13.0 \pm 0.1$ & $3.41 \pm 0.01$ & $7.2 \pm 0.1$ & $0.52 \pm 0.03$ & $35.5 \pm 6.6$ & $33.3 \pm 6.5$ & $2.2 \pm 0.3$ \\
\hline & High & $12.8 \pm 0.2$ & $3.43 \pm 0.01$ & $7.2 \pm 0.1$ & $0.52 \pm 0.03$ & $79.7 \pm 8.7$ & $76.8 \pm 8.7$ & $2.9 \pm 0.1$ \\
\hline \multirow[t]{4}{*}{ Combined } & Control & $13.5 \pm 0.3$ & $3.46 \pm 0.02$ & $6.9 \pm 0.2$ & $0.62 \pm 0.06$ & $23.2 \pm 2.8$ & $20.7 \pm 2.7$ & $1.9 \pm 0.3$ \\
\hline & Low & $13.5 \pm 0.3$ & $3.47 \pm 0.02$ & $6.7 \pm 0.2$ & $0.64 \pm 0.06$ & $29.5 \pm 2.8$ & $27.7 \pm 2.7$ & $1.8 \pm 0.3$ \\
\hline & Medium & $13.5 \pm 0.2$ & $3.45 \pm 0.02$ & $7.1 \pm 0.1$ & $0.68 \pm 0.05$ & $45.1 \pm 5.8$ & $42.9 \pm 5.7$ & $2.2 \pm 0.2$ \\
\hline & High & $13.7 \pm 0.3$ & $3.49 \pm 0.02$ & $7.1 \pm 0.1$ & $0.62 \pm 0.04$ & $90.4 \pm 7.3$ & $86.7 \pm 7.0$ & $3.7 \pm 0.4$ \\
\hline \multirow[t]{3}{*}{$P$ value } & Treatment & 0.402 & 0.194 & 0.156 & 0.348 & $<0.001$ & $<0.001$ & $<0.001$ \\
\hline & Year & 0.007 & $<0.001$ & 0.027 & 0.003 & 0.008 & 0.006 & 0.443 \\
\hline & Treatment $\times$ year & 0.200 & 0.620 & 0.588 & 0.966 & 0.610 & 0.636 & 0.040 \\
\hline
\end{tabular}

$\mathrm{GAE}=$ gallic acid equivalent. 
Ciocalteu's phenol reagent and sodium bicarbonate were purchased from SigmaAldrich (St. Louis, MO).

The Megazyme Primary Amino Nitrogen and Ammonia (Rapid) spectrophotometric assay kits (Bray, Ireland) were used to measure YAN in 96-well microplates according to manufacturer specifications and read on a Molecular Devices Spectramax 384 Plus spectrophotometer (San Jose, CA) at $\lambda 340$ $\mathrm{nm}$. The PAN assay kit measures primary amino nitrogen by a reaction of amino nitrogen in juice samples with $\mathrm{N}$-acetyl-Lcysteine and o-phthaldialdehyde that forms isoindole derivatives that are measured by an increase in absorbance at $\lambda 340 \mathrm{~nm}$. The Ammonia Ion kit functions via the reaction of $\mathrm{NH}_{3}$ with NADPH and 2-Oxoglutarate to yield $\mathrm{NADP}^{+}$, L-glutamic acid, and water; the increase in absorption of $\mathrm{NADP}^{+}$at $\lambda$ $340 \mathrm{~nm}$ is stoichiometric with the amount of $\mathrm{NH}_{3}$ in the sample. The PAN assay kit only measures the concentration of the primary amino nitrogen in amino acids; it does not measure the nitrogen in the amine side chain of asparagine and glutamine, which can be metabolized by Saccharomyces cerevisiae, resulting in an underestimation of YAN (Imada et al., 1973). Despite this shortcoming, the rapid, cost-effective, and repeatable attributes of the PAN assay make it a standard method for estimating FAN in grape and apple juice (Boudreau et al., 2018; Tahim and Mansfield, 2019).

Amino acid quantification and characterization. Amino acid concentrations were quantified using a Waters Corporation AccQ-Tag Ultra Derivatization Kit on an Acquity UPLC (Milford, MA) following the protocol of Ma et al. (2018). Juice samples were centrifuged at $3500 g_{\mathrm{n}}$ for $10 \mathrm{~min}$, filtered through PTFE $0.22-\mu \mathrm{m}$ membrane filters (Micro Solv, Eatontown, NJ) and spiked with an internal standard of L-(+)-norvaline (Acros Organics, NJ) to a final concentration of $2.5 \mathrm{~mm}$. A working standard was made of Waters Amino Acid Hydrolysate Standard and four stock solutions of -norvaline, L-glutamine, $\gamma$-aminobutyric acid, and L-asparagine (Sigma-Aldrich) dissolved in $0.1 \mathrm{~N} \mathrm{HCl}$. The working standard contained $0.25 \mathrm{~mm}$ L-alanine, L-arginine, Laspartic acid, L-glutamic acid, L-glycine, Lhistidine, L-isoleucine, L-leucine, L-lysine, L-methionine, L-phenylalanine, L-proline, L-serine, L-threonine, L-tyrosine, and Lvaline and $0.125 \mathrm{~mm}$ L-cysteine.

Juice samples and standards were derivatized using an AccQ-Tag Ultra Derivatization Kit following manufacturer instructions to generate amino acid derivatives with stable ultraviolet absorbance characters. A Waters AccQ-Tag Ultra Amino Acid Analysis Column (BEH $\mathrm{C}_{18} 1.7-\mu \mathrm{m}$ column) on a Waters $\mathrm{H}-\mathrm{Class}$ UPLC/PDA system was used. Each run had a total run time of $10 \mathrm{~min}$ using the following mobile phases (A-D): A, $100 \%$ AccQ-Tag Ultra eluent A concentrate; B, 90:10 water-AccQ-Tag Ultra eluent B; C, $100 \%$ high-performance liquid chromatography-grade water; D, 100\%
AccQ-Tag Ultra eluent B. Amino acids were detected at $\lambda 260 \mathrm{~nm}$. Empower ${ }^{\mathrm{TM}}$ Software was used to integrate and quantify peaks using the ApexTrack function (Waters Corporation, Milford, MA).

Cider chemistry. Residual sugars in fermented ciders were measured using a Megazyme Sucrose, D-Fructose, and D-Glucose kit in a 96-well microplate spectrophotometric method at $\lambda 340 \mathrm{~nm}$. Through enzymatic oxidation of sucrose, D-fructose, and Dglucose in samples, $\mathrm{NADP}^{+}$is reduced to $\mathrm{NADPH}$, which increases in absorbance at $340 \mathrm{~nm}$ stoichiometrically with the concentration of residual sugars in the cider samples.

Residual $\mathrm{H}_{2} \mathrm{~S}$ in fermented ciders was measured using the method developed by Jastrzembski et al. (2017). Fifteen milliliters of cider was placed in a $125-\mathrm{mL}$ plastic bottle with a 5-cm-long section of tubing attached to the top of a screwcap lid. A Gastec 4LT $\mathrm{H}_{2} \mathrm{~S}$ detector tube was inserted in the end of the tubing (Kitagawa, Japan). A single Alka Seltzer Gold ${ }^{\mathrm{TM}}$ tablet was placed in the bottle, and the screwcap was immediately placed tightly on the bottle. The amount of residual $\mathrm{H}_{2} \mathrm{~S}$ sparged from the $\mathrm{CO}_{2}$ generated by the Alka Seltzer ${ }^{\mathrm{TM}}$ tablet was recorded from the detector tube after the tablet had completely dissolved.

Economic modeling. A partial budget analysis comparing foliar urea application costs with YAN supplementation cost for cider fermentation was calculated. To do this, juice volume from each tree was estimated from the yield, and the cost of foliar urea applications was subtracted from the value of increased juice YAN in comparison with Control juice YAN in each year. The value of each treatment was expressed as dollars per hectare of trees relative to the cost of using Fermaid $\mathrm{O}^{\mathrm{TM}}$, Fermaid $\mathrm{K}^{\mathrm{TM}}$, or diammonium phosphate (DAP) nitrogen supplements. Economic model assumptions are listed in Table 2. Fermaid $\mathrm{O}^{\mathrm{TM}}$ is a blend of yeast autolysates that contains $40 \mathrm{mg} \mathrm{N} / \mathrm{g}$. Fermaid $\mathrm{K}^{\mathrm{TM}}$ is a blend of yeast autolysates and DAP with a YAN concentration of $100 \mathrm{mg} \mathrm{N} / \mathrm{g}$. Both Fermaid products are commercially available yeast nutrient supplements produced by Lallemand Inc. (Montreal, Canada) and commonly used in the cider industry. Diammonium phosphate contains $180 \mathrm{mg} \mathrm{N} / \mathrm{g}$. Juice extraction efficiency was estimated at $0.60 \mathrm{~L} \cdot \mathrm{kg}^{-1}$ fruit using a Lancman 6-Easy-Feed elevator-grinder (Vransko, Slovenia) and a rack and cloth press (81.3 cm model no. 7876; Oesco, Conway, MA) located at the Cornell University Agricultural Experiment Station research orchard in Ithaca, NY.

Statistical analysis. Data were compared using a linear mixed effects model with the number of foliar urea applications as a continuous response variable. Differences were considered significant at $P \leq 0.05$. The number of treatment applications, year, and treatment $\times$ year were included in the model as fixed effects; block, and block $\times$ year were included within the model as random variables. A logit transformation of blush, petiole nitrogen, and amino acid proportion percentage data were performed before analysis to normalize the datasets, but presented as untransformed data. Data were analyzed using JMP Pro version 14 (SAS Institute, Cary, NC).

\section{Results}

Fruit and tree characteristics. Yield and crop load were unaffected by urea application treatment (Table 3). Overall, yields were lower in 2017 than 2018. Fruit receiving more foliar urea applications had less red coloring and greater chlorophyll a content than those receiving fewer urea applications. Fruit from the High treatment had $10 \%$ less red coloration and $18 \%$ greater chlorophyll a content than fruit from the control treatment. There were no differences in fruit mass, firmness, or starch pattern index among treatments. Overall, there was a positive correlation of increased urea applications with greater leaf nitrogen concentrations. Trees in the high treatment had $5 \%$ greater leaf nitrogen concentrations than the control.

Juice chemistry. There were no treatment differences in the soluble solid concentration, $\mathrm{pH}$, titratable acidity, or polyphenol concentration in the juice (Table 4). Yeast assimilable nitrogen concentration was greater in fruit from treatments receiving more urea applications than those receiving fewer applications. Juice from the high treatment had $229 \%$ and $408 \%$ higher YAN concentrations than the control in 2017 and 2018, respectively (Fig. 1). Overall, YAN concentrations in 2017 were $47 \%$ greater than those in 2018 . The majority of YAN in all treatments comprised PAN. Primary amino nitrogen constituted $95 \%$ of YAN in 2017 and $92 \%$ in 2018 . More urea applications increased both PAN and $\mathrm{NH}_{3}$ concentrations in fruit, but the majority of increases in YAN among treatments comprised PAN. Even though $\mathrm{NH}_{3}$ concentrations increased with more urea applications, proportionally less juice YAN comprised $\mathrm{NH}_{3}$ than PAN $(P<0.001$, $R^{2}=0.49$ ).

Amino acid profiles. Asparagine was the most abundant amino acid found in the apple juice from this experiment (Table 5). Asparagine also constituted a greater proportion of FAN in treatments receiving more urea applications than those receiving fewer applications (Fig. 2). Asparagine constituted $73.8 \%$ of the FAN in the high treatment and $53.2 \%$ in the control (Table 6). Aspartic acid and glutamic acid had the second and third greatest proportions of amino acids among all treatments, respectively, and were more abundant in treatments receiving more urea applications. However, aspartic acid and glutamic acid proportionally constituted less of FAN in treatments receiving more urea applications than those receiving fewer. Aspartic acid and glutamic acid constituted $13.8 \%$ and $10.1 \%$ of Control treatment juice FAN but only $5.8 \%$ and $3.8 \%$ of high treatment juice FAN, respectfully. 
Glutamine was the fourth most abundant amino acid and contributed $10.7 \%$ of FAN across all treatments and years (Table 5). However, there was no difference in the proportion of glutamine among treatments (Table 6). The remainder of the FAN within the apple juice samples consisted of serine, alanine, and histidine, which all contributed relatively little to total FAN (Tables 5 and 6). A single high treatment replicate in 2017 contained $1.7 \mathrm{mg} \cdot \mathrm{L}^{-1}$ of methionine, but otherwise both cysteine and methionine concentrations were below the limit of detection.

Fermentation characteristics and cider chemistry. Apple juice from trees receiving more foliar urea applications had greater maximum fermentation rates and finished fermenting sooner than those receiving fewer applications (Table 7). The maximum fermentation rate for the high treatment juice was $147 \%$ and $374 \%$ greater than the control in 2017 and 2018, respectively. Fermentation for the high treatment juice were also $39 \%$ and $45 \%$ shorter in duration than the control. Maximum fermentation rates in 2017 were greater than those in 2018, and fermentation durations were shorter. Much more $\mathrm{H}_{2} \mathrm{~S}$ was produced during fermentations in 2017 than 2018; $\mathrm{H}_{2} \mathrm{~S}$ synthesis was more than 23 -fold

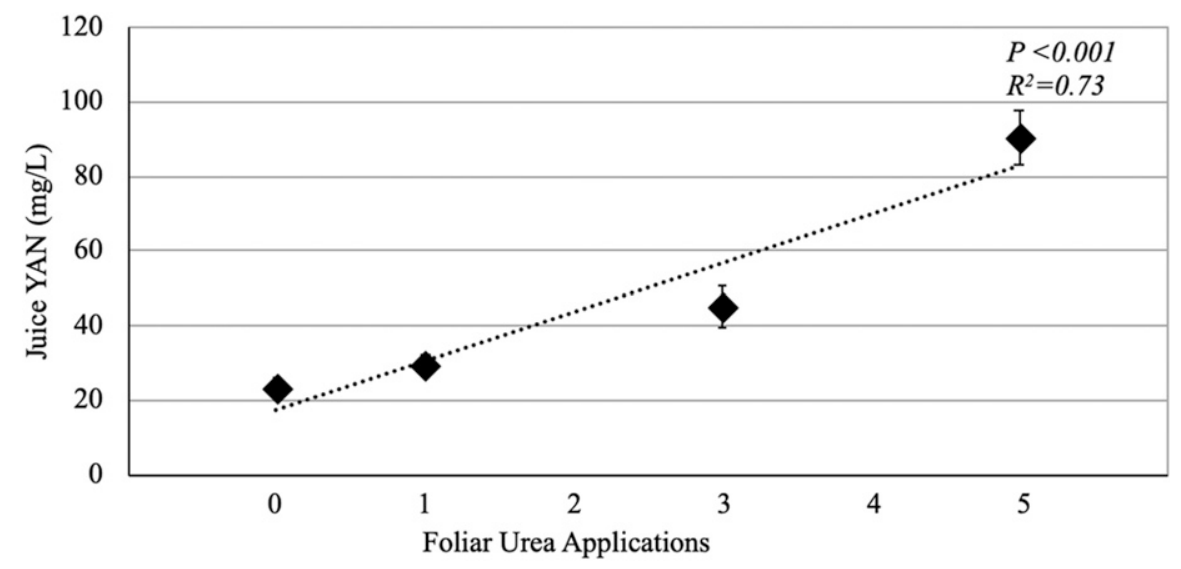

Fig. 1. Yeast assimilable nitrogen (YAN) concentrations in 'Red Spy' apple juice from trees in Lansing, NY, that had 0 (control), 1 (low), 3 (medium), or 5 (high) foliar urea applications. Values are means \pm $\mathrm{SE}(\mathrm{n}=6$ per year$)$. greater in 2017 than 2018. Overall, there was a positive correlation between foliar urea applications and $\mathrm{H}_{2} \mathrm{~S}$ synthesis during fermentation; high treatment fermentations produced $142 \%$ more $\mathrm{H}_{2} \mathrm{~S}$ than the control. However, this correlation was due to a positive correlation of fertilization rate and $\mathrm{H}_{2} \mathrm{~S}$ synthesis in $2017\left(P=0.028, R^{2}=0.29\right)$ but not in $2018\left(P=0.697, R^{2}=0.48\right)$. There were no measurable quantities of residual $\mathrm{H}_{2} \mathrm{~S}$ in ciders from any treatment in either year (data not shown).

Ciders made from the higher foliar urea treatments also contained the lowest residual sugar concentrations. Fermentations from the high and medium treatments had less residual sugar than the control (Table 7). The high treatment had no measurable residual sugars after fermentation in either year. The medium treatment had no measurable residual sugars in 2017. Overall, residual sugar concentrations were greater in 2018 than in 2017. In 2018, residual sugar concentration was 2.3 and $2.2 \mathrm{~g} \cdot \mathrm{L}^{-1}$ in the control and low treatments, respectively.

Economic model. Compared with supplementing juice with Fermaid $\mathrm{O}^{\mathrm{TM}}$, the greater YAN concentration that resulted from the foliar urea applications was estimated to offset the urea application costs, thus resulting in a negative correlation between foliar urea applications and exogenous nitrogen supplementation costs (Fig. 3). To achieve a similar YAN concentration by supplementing juice with Fermaid $\mathrm{O}^{\mathrm{TM}}$, the high treatment was estimated to cost $\$ 1246 /$ ha in 2017 and \$1271/ha in 2018 less than the control (Table 8). Increasing urea application rate was not correlated with the estimated cost of using Fermaid $\mathrm{K}^{\mathrm{TM}}$. Increased YAN concentration was disproportionally greater in the high than in the low and medium treatments. This resulted in the low and medium treatments having a smaller net gain in YAN per urea application than the high treatment. Thus, we calculated a small net positive return for the high treatment when supplementing with Fermaid $\mathrm{K}^{\mathrm{TM}}(\$ 54.80 / \mathrm{ha})$, but small mean negative returns ( $\$-21.50 /$ ha and $\$-41.46 / \mathrm{ha}$, respectively) for the low and medium treatments. Due to the low cost of DAP, increased YAN concentrations from the urea applications did not offset the application costs, and therefore a positive correlation between increasing foliar urea application rate and the cost of supplementing nitrogen was found. Sensitivity analyses for these economic models found that these conclusions were maintained even when increasing the target YAN concentrations up to $300 \mathrm{mg} \cdot \mathrm{L}^{-1}$.

\section{Discussion}

For commercial production of freshmarket apples, modest nitrogen fertilization rates are recommended to maintain sufficient nitrogen status for photosynthesis and fruit cell division and expansion. However, excessive fertilization rates can negatively affect fruit quality and flower bud cold hardiness (Stiles and Reid, 1991). Excess application of nitrogen has been correlated with decreased red and increased green coloration in apples, lower flesh firmness, and reduced fruit quality after long-term storage (Fallahi, 1997; Raese et al., 2007; Wargo et al., 2003, 2004). In this experiment, fruit receiving more urea applications had less red coloration and more chlorophyll. Decreased flesh firmness was

Table 5. Amino acid concentrations from 'Red Spy' apples from trees grown in Lansing, NY, that had 0 (control), 1 (low), 3 (medium), or 5 (high) foliar urea applications. Values are means $\pm \mathrm{SE}(\mathrm{n}=6$ per year $)$.

\begin{tabular}{|c|c|c|c|c|c|c|c|c|c|}
\hline Yr & Treatment & $\begin{array}{l}\text { Asparagine } \\
\left(\mathrm{mg} \cdot \mathrm{L}^{-1}\right)\end{array}$ & $\begin{array}{l}\text { Aspartic acid } \\
\left(\mathrm{mg} \cdot \mathrm{L}^{-1}\right)\end{array}$ & $\begin{array}{c}\text { Glutamic } \\
\text { Acid }\left(\mathrm{mg} \cdot \mathrm{L}^{-1}\right)\end{array}$ & $\begin{array}{l}\text { Glutamine } \\
\left(\mathrm{mg} \cdot \mathrm{L}^{-1}\right)\end{array}$ & $\begin{array}{l}\text { Serine } \\
\left(\mathrm{mg} \cdot \mathrm{L}^{-1}\right)\end{array}$ & $\begin{array}{l}\text { Alanine } \\
\left(\mathrm{mg} \cdot \mathrm{L}^{-1}\right)\end{array}$ & $\begin{array}{l}\text { Histidine } \\
\left(\mathrm{mg} \cdot \mathrm{L}^{-1}\right)\end{array}$ & $\begin{array}{c}\text { Other } \\
\left(\mathrm{mg} \cdot \mathrm{L}^{-1}\right)\end{array}$ \\
\hline \multirow{2}{*}{2017} & Low & $173.8 \pm 30.2$ & $76.4 \pm 5.7$ & $31.9 \pm 1.2$ & $18.6 \pm 2.4$ & $5.7 \pm 0.4$ & $3.3 \pm 0.2$ & $3.0 \pm 0.1$ & $1.1 \pm 0.1$ \\
\hline & Medium & $235.8 \pm 33.6$ & $98.1 \pm 9.3$ & $69.2 \pm 11.5$ & $26.6 \pm 8.0$ & $8.0 \pm 2.3$ & $7.9 \pm 1.5$ & $1.7 \pm 0.8$ & $1.2 \pm 0.3$ \\
\hline \multirow[t]{3}{*}{2018} & Control & $48.9 \pm 11.8$ & $25.4 \pm 1.2$ & $20.6 \pm 1.3$ & $16.9 \pm 2.9$ & $4.7 \pm 0.3$ & $1.3 \pm 0.3$ & $2.9 \pm 0.2$ & $0.8 \pm 0.1$ \\
\hline & Low & $49.7 \pm 11.8$ & $29.8 \pm 4.8$ & $22.9 \pm 1.8$ & $20.8 \pm 2.4$ & $5.9 \pm 1.0$ & $1.6 \pm 0.4$ & $3.1 \pm 0.3$ & $1.4 \pm 0.2$ \\
\hline & Medium & $93.7 \pm 26.0$ & $48.4 \pm 5.3$ & $31.9 \pm 0.6$ & $28.3 \pm 1.1$ & $7.7 \pm 0.6$ & $2.9 \pm 0.4$ & $2.7 \pm 0.2$ & $1.1 \pm 0.2$ \\
\hline \multirow{3}{*}{ Combined } & Low & $119.2 \pm 27.5$ & $57.6 \pm 8.7$ & $27.2 \pm 1.8$ & $18.3 \pm 1.8$ & $6.2 \pm 0.6$ & $2.8 \pm 0.5$ & $3.1 \pm 0.1$ & $1.4 \pm 0.2$ \\
\hline & Medium & $165.1 \pm 30.7$ & $70.2 \pm 9.1$ & $48.2 \pm 7.0$ & $28.2 \pm 3.6$ & $9.1 \pm 1.0$ & $5.3 \pm 0.9$ & $2.5 \pm 0.3$ & $1.3 \pm 0.2$ \\
\hline & High & $581.7 \pm 68.2$ & $90.7 \pm 10.0$ & $63.3 \pm 8.6$ & $52.3 \pm 9.2$ & $23.1 \pm 3.1$ & $15.8 \pm 2.8$ & $3.4 \pm 0.2$ & $3.6 \pm 0.4$ \\
\hline \multirow[t]{3}{*}{$P$ value } & Treatment & $<0.001$ & $<0.001$ & $<0.001$ & $<0.001$ & $<0.001$ & $<0.001$ & 0.324 & $<0.001$ \\
\hline & Year & 0.002 & 0.005 & 0.012 & 0.332 & 0.096 & 0.032 & 0.258 & 0.118 \\
\hline & Treatment $\times$ year & 0.660 & 0.181 & $<0.001$ & 0.022 & 0.010 & 0.007 & 0.995 & 0.002 \\
\hline
\end{tabular}


not observed in our study and would only be considered an important attribute for cider apples if they were going to be stored for long periods. Leaf nitrogen concentration among all treatments were above the recommended minimal threshold for hard-fleshed and processing apples (Stiles and Reid, 1991). Although these attributes are less important quality characteristics for cider apples, these results show that many aspects of fruit physiology were altered by the urea treatments. Further research should determine the upper threshold for urea application rates because at some level, the negative consequences on tree physiology or fruit quality will likely exceed the benefits we found.

A previously published study investigating nitrogen fertilization of apple trees for cider production was conducted by Lea and Beech (1978). In their study, 3-year-old 'Dabinett' apple trees were transplanted into pots filled with sand and then either fertilized with nitrogen or left unfertilized for a single growing season. Fruit from unfertilized trees
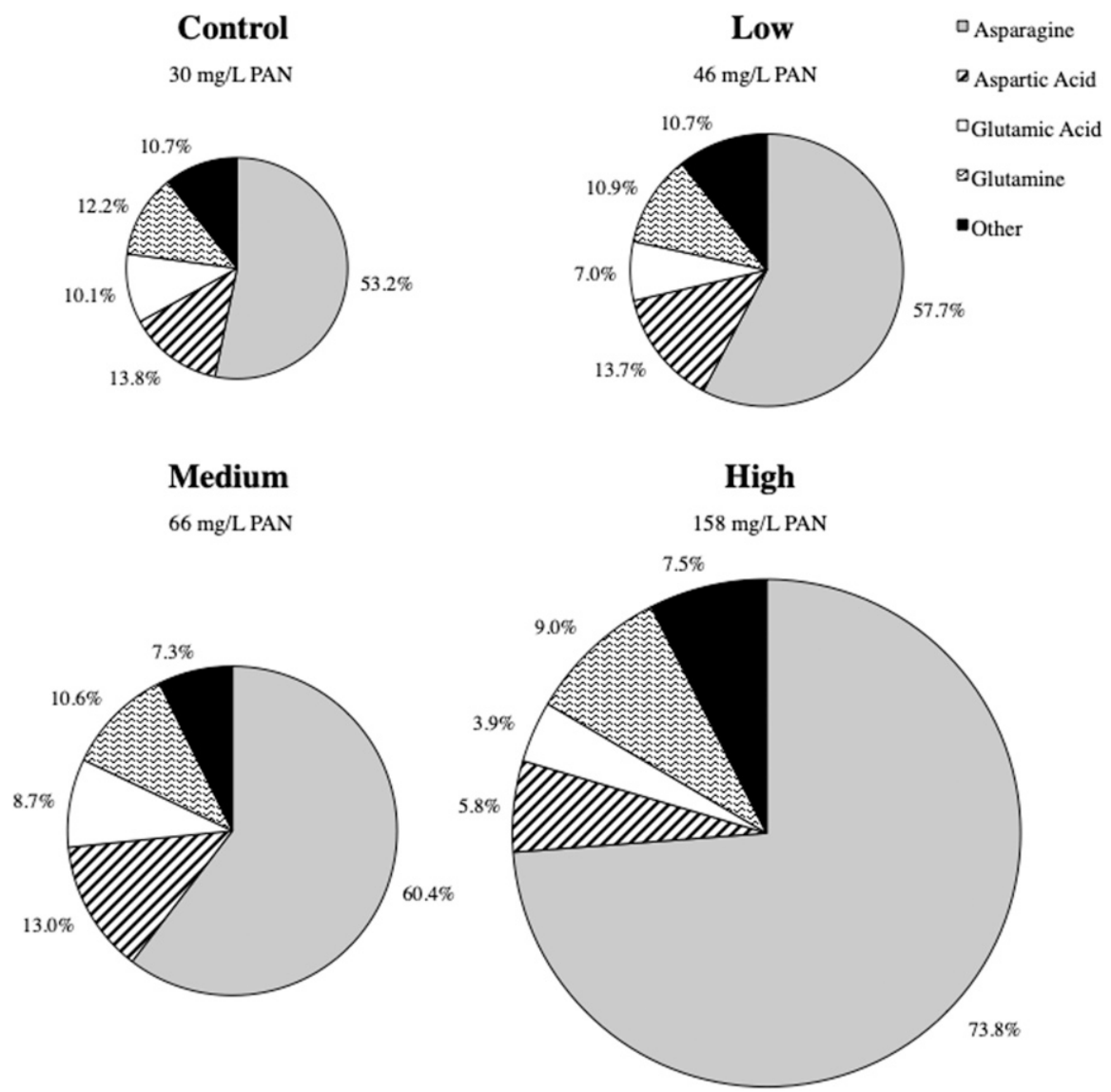

Fig. 2. Total concentrations of primary amino nitrogen (PAN) and proportions of amino acids constituting apple juice PAN from 'Red Spy' apple trees in Lansing, NY, that had 0 (control), 1 (low), 3 (medium), or 5 (high) foliar urea applications. Pie chart sizes are to scale of PAN concentration among the treatments. Data represent a "combined" mean from both years of the study.

had $17 \%$ greater total polyphenol concentration compared with fertilized trees, as well as a $35 \%$ decrease in fruit yield. This study is often referenced as evidence that nitrogen fertilization limits polyphenol production in apples, but the greater decrease in yield than polyphenol content illustrates that mean total fruit polyphenol production per tree was potentially greater for the fertilized trees. In other words, polyphenols were more diluted in a larger crop, but the total fruit polyphenol production per tree was similar or greater in fertilized trees. Our study found that foliar urea applications did not affect total polyphenol concentrations by total juice volume or total polyphenols on a per tree basis. Furthermore, procyanidins, the polyphenols that contribute the majority of astringency and bitterness to hard ciders, are mostly produced during the cell division phase of fruit growth (Renard et al., 2007). Therefore, applications in the 6 weeks before harvest would have been after procyanidin biosynthesis subsided, and thus the urea treatments were unlikely to affect procyanidin concentration in the harvested fruit.

Although foliar nitrogen applications were made in the form of urea, an ammonia-based fertilizer, nearly all of the increases in YAN in juice were attributable to organic nitrogen compounds (FAN or amino acids), rather than inorganic compounds (ammonium ions). Cultivar and season have also been found to be better predictors of YAN composition in wine grapes than the form of nitrogen fertilizer (Garde-Cerdán et al., 2017). The proportional increase of asparagine to other major amino acids in our study was similar to the work by Sugimoto et al. (2011), who found concentrations of aspartic acid, glutamine, and glutamic acid to decrease earlier than asparagine as 'Jonagold' apples matured. Additionally, Sugimoto et al. (2011) found asparagine metabolism to be inactive and other predominant amino acids to be actively metabolized during the timeframe that we made the urea applications in our experiment. Cheng et al. (2004) also found that higher rates of nitrogen fertilization resulted in an increasing proportion of both free amino acids and proteins in apple tree tissue to be composed of asparagine.

Table 6. Proportion of amino acids constituting primary amino nitrogen from 'Red Spy' apples from trees grown in Lansing, NY, that had 0 (control), 1 (low), 3 (medium), or 5 (high) foliar urea applications. Values are means $\pm \mathrm{SE}$ ( $\mathrm{n}=6$ per year).

\begin{tabular}{|c|c|c|c|c|c|c|c|c|c|}
\hline$\overline{\mathrm{Yr}}$ & Treatment & Asparagine (\%) & Aspartic acid (\%) & Glutamic acid (\%) & Glutamine $(\%)$ & Serine $(\%)$ & Alanine (\%) & Histidine (\%) & Other $(\%)$ \\
\hline \multirow[t]{3}{*}{$\overline{2017}$} & Control & $59.5 \pm 4.6$ & $14.3 \pm 1.6$ & $10.2 \pm 1.2$ & $7.1 \pm 1.3$ & $2.0 \pm 0.4$ & $2.5 \pm 0.1$ & $2.4 \pm 0.3$ & $3.5 \pm 0.7$ \\
\hline & Medium & $69.1 \pm 2.5$ & $13.1 \pm 0.8$ & $7.4 \pm 1.3$ & $6.3 \pm 1.4$ & $1.7 \pm 0.3$ & $7.1 \pm 0.2$ & $0.8 \pm 0.4$ & $1.5 \pm 0.4$ \\
\hline & High & $70.8 \pm 3.9$ & $6.8 \pm 1.1$ & $4.1 \pm 0.8$ & $10.6 \pm 3.8$ & $2.4 \pm 0.5$ & $1.9 \pm 0.3$ & $0.6 \pm 0.1$ & $2.8 \pm 0.5$ \\
\hline \multirow{3}{*}{2018} & Low & $41.5 \pm 5.5$ & $13.9 \pm 0.9$ & $10.5 \pm 1.5$ & $18.6 \pm 2.1$ & $3.6 \pm 0.5$ & $1.0 \pm 0.2$ & $4.4 \pm 1.2$ & $6.4 \pm 0.6$ \\
\hline & Medium & $50.4 \pm 5.4$ & $14.5 \pm 1.0$ & $9.3 \pm 1.5$ & $16.3 \pm 2.2$ & $3.0 \pm 0.3$ & $1.3 \pm 0.1$ & $2.2 \pm 0.2$ & $3.0 \pm 0.2$ \\
\hline & High & $78.9 \pm 4.1$ & $5.9 \pm 0.9$ & $3.6 \pm 0.8$ & $6.5 \pm 1.8$ & $1.8 \pm 0.3$ & $1.0 \pm 0.1$ & $0.8 \pm 0.3$ & $1.8 \pm 0.1$ \\
\hline \multirow{2}{*}{ Combined } & Medium & $60.4 \pm 4.0$ & $13 \pm 0.8$ & $8.7 \pm 0.9$ & $10.6 \pm 2.0$ & $2.2 \pm 0.3$ & $1.5 \pm 0.3$ & $1.3 \pm 0.3$ & $2.2 \pm 0.3$ \\
\hline & High & $73.8 \pm 2.9$ & $5.8 \pm 0.7$ & $3.9 \pm 0.5$ & $8.6 \pm 1.8$ & $2.2 \pm 0.4$ & $1.8 \pm 0.4$ & $0.7 \pm 0.12$ & $2.2 \pm 0.3$ \\
\hline \multirow[t]{3}{*}{$P$ value } & Treatment & $<0.001$ & $<0.001$ & $<0.001$ & 0.113 & 0.209 & 0.004 & $<0.001$ & 0.004 \\
\hline & Year & 0.005 & 0.934 & 0.158 & 0.010 & 0.007 & 0.041 & 0.008 & 0.014 \\
\hline & Treatment $\times$ year & 0.013 & 0.627 & 0.414 & 0.003 & 0.005 & 0.018 & 0.064 & 0.034 \\
\hline
\end{tabular}


Table 7. Fermentation characteristics of 'Red Spy' apple juice from trees grown in Lansing, NY, that had 0 (control), 1 (low), 3 (medium), or 5 (high) foliar urea applications and fermented with UCD 522 yeast. Values are means \pm SE $(n=6$ per year $)$.

\begin{tabular}{|c|c|c|c|c|c|}
\hline Yr & Treatment & $\begin{array}{l}\text { Maximum fermentation } \\
\text { rate }(\mathrm{mg} \text { sugar } / \mathrm{L} / \mathrm{h})\end{array}$ & $\begin{array}{c}\text { Fermentation duration } \\
\text { (days) }\end{array}$ & $\begin{array}{c}\text { Hydrogen sulfide } \\
\text { production }\left(\mu \mathrm{g} \cdot \mathrm{L}^{-1}\right)\end{array}$ & $\begin{array}{c}\text { Residual } \\
\text { sugar }\left(g \cdot \mathrm{L}^{-1}\right)\end{array}$ \\
\hline 2017 & Low & $278 \pm 104$ & $16.3 \pm 1.0$ & $58.1 \pm 16.3$ & $0.1 \pm 0.0$ \\
\hline \multirow[t]{3}{*}{2018} & Control & $31 \pm 4$ & $27.7 \pm 1.5$ & $0.0 \pm 0.0$ & $2.3 \pm 0.6$ \\
\hline & Low & $31 \pm 4$ & $26.6 \pm 0.7$ & $4.6 \pm 3.9$ & $2.2 \pm 0.7$ \\
\hline & Medium & $63 \pm 14$ & $24.3 \pm 2.0$ & $6.3 \pm 4.9$ & $0.7 \pm 0.5$ \\
\hline \multirow{3}{*}{ Combined } & Low & $155 \pm 30$ & $21.5 \pm 1.6$ & $31.4 \pm 11.4$ & $1.1 \pm 0.5$ \\
\hline & Medium & $215 \pm 48$ & $18.7 \pm 2.0$ & $60.4 \pm 19.1$ & $0.4 \pm 0.3$ \\
\hline & High & $339 \pm 61$ & $13.1 \pm 1.2$ & $48.6 \pm 17.9$ & $0.0 \pm 0.0$ \\
\hline \multirow[t]{3}{*}{$P$ value } & Treatment & $<0.001$ & $<0.001$ & 0.030 & $<0.001$ \\
\hline & Year & $<0.001$ & $<0.001$ & $<0.001$ & 0.077 \\
\hline & Treatment $\times$ year & $<0.001$ & 0.050 & 0.037 & 0.131 \\
\hline
\end{tabular}

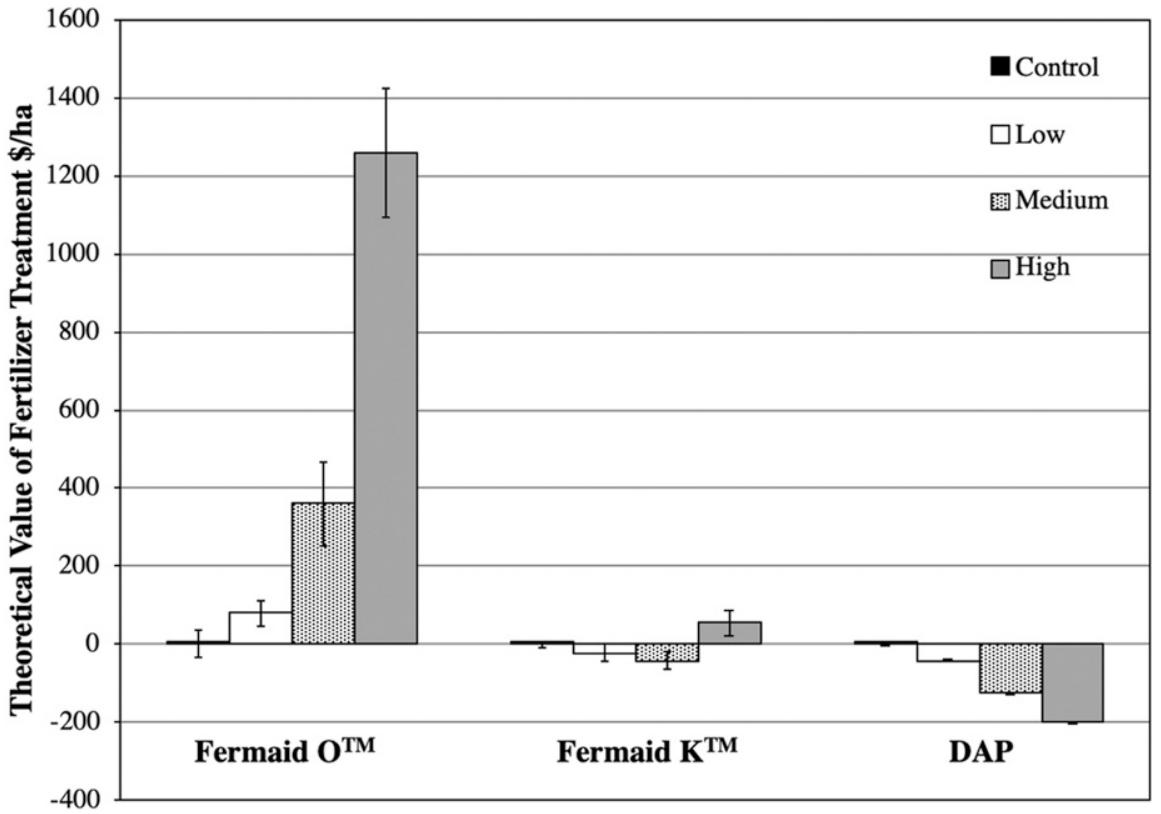

Fig. 3. The theoretical cost of applying foliar urea to 'Red Spy' apple trees grown in in Lansing, NY, that had 0 (control), 1 (low), 3 (medium), or 5 (high) foliar urea applications vs. adding exogenous yeast assimilable nitrogen in the form of Fermaid $\mathrm{O}^{\mathrm{TM}}$, Fermaid $\mathrm{K}^{\mathrm{TM}}$, or diammonium phosphate (DAP). Values are means \pm SE $(n=6$ per year $)$.

Furthermore, asparagine and glutamine each contain two nitrogen atoms; thus, these compounds are more carbon efficient at storing nitrogen than the other predominant amino acids found in this study that contained a single nitrogen atom.

Asparagine, aspartic acid, glutamic acid, glutamine, serine, and alanine are reportedly preferentially metabolized by $S$. cerevisiae yeast (Waterhouse et al., 2016). These amino acids are selectively used because they require fewer intermediary steps to donate nitrogen in de novo amino acid synthesis than the nonpreferred amino acids. Histidine, of which there was $<4 \mathrm{mg} \cdot \mathrm{L}^{-1}$ among all treatments and years, was the only amino acid that constituted $>1 \%$ of FAN from juice samples in this study that is considered to be in the nonpreferred class of amino nitrogen. Therefore, nearly all of the increases in YAN from the urea applications were in forms preferentially metabolized by yeast during fermentation.

In our study, the greater YAN concentration resulted in faster and more complete fermentation of reducing sugars. The correlation between increasing YAN and increased fermentation rate and, conversely, the propensity for low YAN grape juice to result in incomplete fermentations are well established (Bell and Henschke, 2005). Greater YAN concentrations have also been correlated with increasing volatile aromatic compound production, including fusel alcohols and acetate esters derived from amino acid metabolism, and ethyl esters, primarily produced from yeast fatty acid metabolism (Santos et al., 2015; Torrea et al., 2011). Supplementing grape must with amino acids resulted in different volatile aromatic profiles from the finished wines than those supplemented with ammonia, but the causal mech- anisms have not been well described (Torrea et al., 2011). How alterations in aromatic compounds affects sensory characteristics remains an area of active research (Tahim and Mansfield, 2019). Additionally, research into the relationships among the concentrations and forms of YAN on fermentation kinetics and sensory properties has primarily been performed on grape-based wine and not cider. Identifying the volatile aromatic compounds that can be altered by increasing YAN with foliar urea applications in apple orchards needs further study.

The economic analyses demonstrated that a preharvest urea spray program has the potential to be a cost-effective way to increase apple juice FAN. Specifically, foliar urea applications could be less costly than Fermaid $\mathrm{O}^{\mathrm{TM}}$. Furthermore, foliar urea applications would likely result in a juice composition comparable to what would be obtained with Fermaid $\mathrm{O}^{\mathrm{TM}}$ because the greatest increases were in FAN, the primary nitrogen source in Fermaid $\mathrm{O}^{\mathrm{TM}}$. We also found that foliar urea applications were comparable to the cost of exogenous Fermaid $\mathrm{K}^{\mathrm{TM}}$ additions. However, because DAP is fairly inexpensive, exogenous DAP additions to juice would likely be less expensive than foliar urea applications. In our discussions with cider producers, many stated a preference for using organic forms of nitrogen (such as the proprietary Fermaid products) over inorganic nitrogen in the form of DAP. Further studies should compare nitrogen composition, fermentation kinetics, and cider quality between urea treated fruit and the exogenous nitrogen supplements.

We found that increasing the number of urea applications was correlated with greater $\mathrm{H}_{2} \mathrm{~S}$ production in the first year of the study. Although this is the opposite of what we hypothesized would occur, increase in $\mathrm{H}_{2} \mathrm{~S}$ production in juice with high YAN concentrations has been observed in other studies for both grape wine and hard cider (Boudreau et al., 2017a; Jiranek et al., 1995; Ugliano et al., 2009). The fermentations we conducted in 2017 had a much greater $\mathrm{H}_{2} \mathrm{~S}$ synthesis rates than in 2018 , and thus the year had a greater impact on $\mathrm{H}_{2} \mathrm{~S}$ than did the increasing 
Table 8. Partial budget analyses comparing 0 (control), 1 (low), 3 (medium), or 5 (high) foliar urea application costs on 'Red Spy' apple trees grown in Lansing, $\mathrm{NY}$, with three common exogenous yeast assimilable nitrogen supplements. Values are means $\pm \mathrm{SE}(\mathrm{n}=6$ per year).

\begin{tabular}{|c|c|c|c|c|}
\hline$\overline{\mathrm{Yr}}$ & Treatment & Fermaid $\mathrm{O}^{\mathrm{TM}}(\$ / \mathrm{ha})$ & Fermaid $\mathrm{K}^{\mathrm{TM}}(\$ / \mathrm{ha})$ & Diammonium phosphate $(\$ / \mathrm{ha})$ \\
\hline \multirow[t]{3}{*}{2017} & Control & $3.69 \pm 69.55$ & $0.69 \pm 13.09$ & $0.06 \pm 1.15$ \\
\hline & Medium & $370.96 \pm 133.91$ & $-39.42 \pm 25.38$ & $-126.25 \pm 2.21$ \\
\hline & High & $1,245.93 \pm 250.25$ & $52.45 \pm 47.11$ & $-200.09 \pm 4.12$ \\
\hline \multirow{3}{*}{2018} & Low & $91.51 \pm 45.75$ & $-19.19 \pm 8.61$ & $-42.61 \pm 0.75$ \\
\hline & Medium & $349.31 \pm 186.12$ & $-43.50 \pm 35.03$ & $-126.61 \pm 3.07$ \\
\hline & High & $1,270.91 \pm 237.87$ & $57.15 \pm 44.78$ & $-199.67 \pm 3.92$ \\
\hline \multirow{2}{*}{ Combined } & Medium & $360.13 \pm 109.36$ & $-41.46 \pm 20.58$ & $-126.43 \pm 1.80$ \\
\hline & High & $1,258.42 \pm 164.64$ & $54.80 \pm 30.99$ & $-199.88 \pm 2.71$ \\
\hline \multirow[t]{3}{*}{$P$ value } & Treatment & 0.002 & 0.184 & $<0.001$ \\
\hline & Year & $<0.001$ & 0.129 & $<0.001$ \\
\hline & Treatment $\times$ year & $<0.001$ & 0.010 & $<0.001$ \\
\hline
\end{tabular}

urea treatments. Other nutrient deficiencies, such as thiamin and pantothenic acid, may have led to greater $\mathrm{H}_{2} \mathrm{~S}$ production in 2017 (Wainwright, 1971; Wang et al., 2003). Additionally, $\mathrm{H}_{2} \mathrm{~S}$ is an intermediary compound formed from the reduction of sulfate or sulfite to synthesize the sulfur containing amino acids cysteine and methionine, and so there may have been specific amino acid ratios that caused the year-to-year, but not treatment, differences (Ono et al., 1999). Although it is not clear what caused $\mathrm{H}_{2} \mathrm{~S}$ production during our experiment, all of the treatments resulted in a lower YAN concentrations than the 140 $\mathrm{mg} \cdot \mathrm{L}^{-1}$ that is commonly suggested as a minimum threshold for preventing $\mathrm{H}_{2} \mathrm{~S}$ during wine production (Bell and Henschke, 2005). Developing cider-specific YAN and amino acid recommendations should be the focus of targeted research projects.

In our study, $\mathrm{H}_{2} \mathrm{~S}$ synthesis was measured early in the fermentation and no residual $\mathrm{H}_{2} \mathrm{~S}$ was found in the finished ciders. The sparging of $\mathrm{CO}_{2}$ and daily stirring of ciders to keep yeast in suspension may have resulted in the removal of $\mathrm{H}_{2} \mathrm{~S}$ during fermentation. The $\mathrm{H}_{2} \mathrm{~S}$ detector tubes that we used rely on mass transfer of $\mathrm{CO}_{2}$ to pass through the detector tubes and may have been affected by the varying fermentation rates among the treatments. Additionally, wines containing $\mathrm{H}_{2} \mathrm{~S}$ are known to undergo reactions to form mercaptans and other complex sulfide compounds with negative sensory attributes that we did not measure in our study (Waterhouse et al., 2016). Anecdotally, sulfurous aromas were not smelled in finished ciders from this experiment. Our experiment was not designed to include sensory evaluations as we performed the fermentations in small volumes.

\section{Conclusion}

Our study demonstrated that preharvest foliar applications of urea are effective at increasing YAN in apple juice, which can have positive benefits for cider fermentation. Additionally, nearly all of the increases in YAN concentration were in the form of FAN, with asparagine constituting the majority of amino nitrogen. Increasing YAN concentra- tion resulted in faster and more complete fermentations of reducing sugars. The increased FAN concentrations were shown to be an economically advantageous alternative to exogenous FAN additions to the juice. Although commercial apple growers in the United States are not compensated for making additional foliar nutrient applications to help increase juice YAN, a vertically integrated orchard and cidery could find these applications to simultaneously fertilize their orchards and improve the quality of their apples and resulting cider. The nitrogen cycle from the orchard to fermentation remains a complex topic and a major challenge for cider producers, and thus continued research on this topic is necessary for the continued success of the U.S. cider industry.

\section{Literature Cited}

Agnello, A., B. Brown, J. Carroll, L. Cheng, K. Cox, P. Curtis, M. Helms, D. Kain, and T. Robinson. 2019. Cornell pest management guidelines for commercial tree fruit production. Cornell Coop, Ext., Ithaca, NY.

Alcohol and Tobacco Tax and Trade Bureau. 2008. Alcohol and Tobacco Tax and Trade Bureau Statistical Report-Wine: 2007.

Alcohol and Tobacco Tax and Trade Bureau. 2018. Alcohol and Tobacco Tax and Trade Bureau Statistical Report-Wine: 2017.

Ángeles Pozo-Bayón, M., I. Andújar-Ortiz, and M.V. Moreno-Arribas. 2009. Scientific evidences beyond the application of inactive dry yeast preparations in winemaking. Food Res. Int. 42:754-761.

Bell, S.-J. and P.A. Henschke. 2005. Implications of nitrogen nutrition for grapes, fermentation and wine. Austral. J. Grape Wine Res. 11:242-295.

Blanpied, G.D. and K.J. Silsby. 1992. Predicting Harvest Date Windows for Apples. Bulletin 221. Cornell Coop, Ext., Ithaca, NY.

Boudreau, T.F., G.M. Peck, S. Ma, N. Patrick, S. Duncan, S.F. O'Keefe, and A.C. Stewart. 2017a. Hydrogen sulphide production during cider fermentation is moderated by prefermentation methionine addition. J. Inst. Brew. 23:553-561.

Boudreau, T.F., G.M. Peck, S.F. O'Keefe, and A.C. Stewart. 2017b. The interactive effect of fungicide residues and yeast assimilable nitrogen on fermentation kinetics and hydrogen sulfide production during cider fermentation. J. Sci. Food Agr. 97:693-704.
Boudreau, T.F., G.M. Peck, S.F. O'Keefe, and A.C. Stewart. 2018. Free amino nitrogen concentration correlates to total yeast assimilable nitrogen concentration in apple juice. Food Sci. Nutr. 6:119-123.

Butzke, C.E. and L.F. Bisson. 1997. Ethyl carbamate preventative action manual. UC Davis Coop. Ext., Davis, CA.

Charoenchai, C., G.H. Fleet, and P.A. Henschke. 1998. Effects of temperature, $\mathrm{pH}$, and sugar concentration on the growth rates and cell biomass of wine yeasts. Amer. J. Enol. Viticult. 49:283-288.

Cheng, L. and L.H. Fuchigami. 2002. Growth of young apple trees in relation to reserve nitrogen and carbohydrates. Tree Physiol. 22:12971303.

Cheng, L., F. Ma, and D. Ranwala. 2004. Nitrogen storage and its interaction with carbohydrates of young apple trees in response to nitrogen supply. Tree Physiol. 24:91-98.

Cheng, L. and R. Raba. 2009. Accumulation of macro- and micronutrients and nitrogen demand-supply relationship of 'Gala'/"Malling 26' apple trees grown in sand culture. J. Amer. Soc. Hort. Sci. 134:3-13.

Crépin, L., T. Nidelet, I. Sanchez, S. Dequin, and C. Camarasa. 2012. Sequential use of nitrogen compounds by Saccharomyces cerevisiae during wine fermentation: A model based on kinetic and regulation characteristics of nitrogen permeases. Appl. Environ. Microbiol. 78:8102-8111.

Dong, S., L. Cheng, C. Scagel, and L. Fuchigami. 2005. Timing of urea application affects leaf and root $\mathrm{N}$ uptake in young Fuji/M.9 apple trees. J. Hort. Sci. Biotechnol. 80:116-120.

Fallahi, E. 1997. Preharvest nitrogen optimization for maximizing yield and postharvest fruit quality of apples. Acta Hort. 448:415-420.

Fallahi, E., W.S. Conway, K.D. Hickey, and C.E. Sams. 1997. The role of calcium and nitrogen in postharvest quality and disease resistance of apples. HortScience 32:831-835.

Farris, J., G. Peck, and G. Groover. 2013. Assessing the economic feasibility of growing specialized apple cultivars for sale to commercial hard cider producers. Virginia Tech Coop, Ext., Blacksburg, VA.

Garde-Cerdán, T. and C. Ancín-Azpilicueta. 2008. Effect of the addition of different quantities of amino acids to nitrogen-deficient must on the formation of esters, alcohols, and acids during wine alcoholic fermentation. LWS Food Sci. Technol. 41:501-510.

Garde-Cerdán, T., G. Gutiérrez-Gamboa, J. Portu, J.I. Fernández-Fernández, and R. Gil-Muñoz. 
2017. Impact of phenylalanine and urea applications to Tempranillo and Monastrell vineyards on grape amino acid content during two consecutive vintages. Food Res. 102: 451-457.

Herraiz, T. and C.S. Ough. 1993. Formation of ethyl esters of amino acids by yeasts during the alcoholic fermentation of grape juice. Amer. J. Enol. Viticult. 44:41-48.

Imada, A., S. Igarasi, K. Nakahama, and M. Isono. 1973. Asparaginase and glutaminase activities of micro-organisms. Microbiology 76:85-99.

Jastrzembski, J.A., R.B. Allison, E. Friedberg, and G.L. Sacks. 2017. Role of elemental sulfur in forming latent precursors of $\mathrm{H}_{2} \mathrm{~S}$ in wine. J. Agr. Food Chem. 65:10542-10549.

Jiranek, V., P. Langridge, and P.A. Henschke. 1995. Regulation of hydrogen sulfide liberation in wine-producing Saccharomyces cerevisiae strains by assimilable nitrogen. Appl. Environ. Microbiol. 61:461-467.

Lea, A.G.H. and F.W. Beech. 1978. The phenolics of ciders: Effect of cultural conditions. J. Sci. Food Agr. 29:493-496.

Ma, S., A.P. Neilson, J. Lahne, G.M. Peck, S.F. O'Keefe, and A.C. Stewart. 2018. Free amino acid composition of apple juices with potential for cider making as determined by UPLC-PDA. J. Inst. Brew. 124:467-476.

Merwin, I.A. and W.C. Stiles. 1994. Orchard groundcover management impacts on apple tree growth and yield, and nutrient availability and uptake. J. Amer. Soc. Hort. Sci. 119:209215.

Moss, J.R. 2016. Evaluation of nitrogen management schemes in cover cropped vineyards. MS Thesis, Virginia Polytechnic Institute and State Univ., Blacksburg, VA.

Ono, B.-I., T. Hazu, S. Yoshida, T. Kawato, S. Shinoda, J. Brzvwczy, and A. Paszewski. 1999. Cysteine biosynthesis in Saccharomyces cerevisiae: A new outlook on pathway and regulation. Yeast 15(13):1365-1375.

Peck, G. and W. Knickerbocker. 2018. Economic case studies of cider apple orchards in New York State. Fruit Qrtly. 26:5-10.

Peck, G., M. McGuire, T. Boudreau, and A. Stewart. 2016. Crop load density affects 'York' apple juice and hard cider quality. HortScience 51:1098-1102.

Raese, J.T., S. R. Drake, and E.A. Curry. 2007. Nitrogen fertilizer influences fruit quality, soil nutrients and cover crops, leaf color and nitrogen content, biennial bearing and cold hardi- ness of 'Golden Delicious'. J. Plant Nutr 30:1585-1604.

Renard, C.M.G.C., N. Dupont, and P. Guillermin. 2007. Concentrations and characteristics of procyanidins and other phenolics in apples during fruit growth. Phytochemistry 68:11281138.

Saerens, S.M.G., F.R. Delvaux, K.J. Verstrepen, and J.M. Thevelein. 2010. Production and biological function of volatile esters in Saccharomyces cerevisiae. Microb. Biotechnol. 3: 165-177.

Santos, C.M.E., A. Alberti, G. Pietrowski, A.A.F. Zielinski, G. Wosiacki, A. Nogueira, and R.M.M. Jorge. 2016. Supplementation of amino acids in apple must for the standardization of volatile compounds in ciders. J. Inst. Brew. 122:334-341.

Santos, C.M.E., G. Pietrowski, C.M. Braga, M.J. Rossi, J. Ninow, T.P.M. Santos, and A. Nogueira. 2015. Apple amino acid profile and yeast strains in the formation of fusel alcohols and esters in cider production. J. Food Sci. 80:1170-1177.

Singleton, V.L. and J.A. Rossi. 1965. Colorimetry of total phenolics with phosphomolybdicphosphotungstic acid reagents. Amer. J. Enol. Viticult. 16:144-158.

Soil Survey Staff. 2014. Keys to soil taxonomy. 12 th ed. U.S. Dept. Agr.

Stiles, W.C. and W.S. Reid. 1991. Orchard nutrition management. Information Bulletin 219. Cornell Coop. Ext., Ithaca, NY.

Sugimoto, N., A.D. Jones, and R. Beaudry. 2011. Changes in free amino acid content in 'Jonagold' apple fruit as related to branched-chain ester production, ripening, and senescence. J. Amer. Soc. Hort. Sci. 136:429-440.

Sumby, K.M., P.R. Grbin, and V. Jiranek. 2010. Microbial modulation of aromatic esters in wine: Current knowledge and future prospects. Food Chem. 121:1-16.

Tahim, C.M. and A.K. Mansfield. 2019. Yeast assimilable nitrogen optimization for coolclimate Riesling. Amer. J. Enol. Viticult. 70: 127-138.

Torrea, D., C. Varela, M. Ugliano, C. AncinAzpilicueta, I. Leigh Francis, and P.A. Henschke. 2011. Comparison of inorganic and organic nitrogen supplementation of grape juice-effect on volatile composition and aroma profile of a Chardonnay wine fermented with Saccharomyces cerevisiae yeast. Food Chem. 127:1072-1083.
Ugliano, M., B. Fedrizzi, T. Siebert, B. Travis, F. Magno, G. Versini, and P.A. Henschke. 2009. Effect of nitrogen supplementation and Saccharomyces species on hydrogen sulfide and other volatile sulfur compounds in Shiraz fermentation and wine. J. Agr. Food Chem. 57:4948-4955.

Ugliano, M. and P.A. Henschke. 2010. Comparison of three methods for accurate quantification of hydrogen sulfide during fermentation. Anal. Chim. Acta 660:87-91.

Vilanova, M., M. Ugliano, C. Varela, T. Siebert, I.S. Pretorius, and P.A. Henschke. 2007. Assimilable nitrogen utilisation and production of volatile and non-volatile compounds in chemically defined medium by Saccharomyces cerevisiae wine yeasts. Appl. Microbiol. Biotechnol. 77:145-157.

Wainwright, T. 1971. Production of $\mathrm{H}_{2} \mathrm{~S}$ by yeasts: Role of nutrients. J. Appl. Bacteriol. 34:161-171.

Wang, H. and L. Cheng. 2011. Differential effects of nitrogen supply on skin pigmentation and flesh starch breakdown of 'Gala' apple. HortScience 46:1116-1120.

Wang, X.D., J.C. Bohlscheid, and C.G. Edwards. 2003. Fermentative activity and production of volatile compounds by Saccharomyces grown in synthetic grape juice media deficient in assimilable nitrogen and/or pantothenic acid. J. Appl. Microbiol. 94:349-359.

Wargo, J.M., I.A. Merwin, and C.B. Watkins. 2003. Fruit size, yield, and market value of 'GoldRush' apple are affected by amount, timing and method of nitrogen fertilization. HortTechnology 13:153-161.

Wargo, J.M., I.A. Merwin, and C.B. Watkins. 2004. Nitrogen fertilization, midsummer trunk girdling, and AVG treatments affect maturity and quality of 'Jonagold' apples. HortScience 39:493-500.

Waterhouse, A., G. Sacks, and D. Jeffery. 2016. Understanding wine chemistry. Wiley Online Library. doi: 10.1002/9781118730720.

Witte, C.P. 2011. Urea metabolism in plants. Plant Sci. 180:431-438.

Xia, G., L. Cheng, A. Lakso, and M. Goffinet. 2009. Effects of nitrogen supply on source-sink balance and fruit size of 'Gala' apple trees. J. Amer. Soc. Hort. Sci. 134:126-133.

Xu, Y., W. Fan, and M.C. Qian. 2007. Characterization of aroma compounds in apple cider using solvent-assisted flavor evaporation and headspace solid-phase microextraction. J. Agr. Food Chem. 55:3051-3057. 